\title{
The Diagnosis of Leprosy with Special Reference to Tissue Defense
}

\author{
(Being the Stephen Rothman Memorial Lecture, 1964 , \\ Delivered at the Annual Meeting of the \\ American Academy of Dermatology on December 6, 1964 by \\ R. G. GOGHRÄN, M.D., F.R.C.P., D.T.M. and H.)
}

INTRODUCTION

I cannot adequately express my sense of gratitude and privilege to be invited to give this Stephen Rothman Memorial lecture (I 964). I only had the privilege of meeting Dr Rothman on three occasions when in Chicago, and the last time I saw him, he greeted me in terms of lighthearted humour which was so well known to his friends with the remark, 'Here is the person who tells me the cases of sarcoid among my negro patients in Illinois are most probably leprosy'. To have even this slight acquaintance with this remarkable personality leaves an indelible impression on one's mind. I gladly pay homage to one who was outstanding in his profession, a leader of men, and to borrow a phrase from Professor Lorincz, an unchallenged master of investigative dermatology.

I do not feel competent to address this Academy, but I trust that what I say will help in the better understanding of one of the most complex of all diseases. I shall endeavour to show that when clinical leprosy is related to a more detailed study of the pathology of disease, leprosy then becomes a magnificent tool for the elucidation of the many still unsolved problems in dermatological practice and particularly problems which are associated with the autoimmune diseases and the collagen disorders. By so doing, I shall be relating clinical observations to fundamental studies. Ladies and gentlemen, I think in this way I shall be following, in a very small way, the great master of dermatology in putting my footsteps into the broad path left by this giant of men of whom all his friends acclaim in terms of great enthusiasm, that here is a prince among investigative dermatologists. Well deserved tributes were showered on Professor Rothman not only because of his erudition, but because of his enchanting humanity and lively personality, and his outstanding qualities made
Professor Rothman a scientist of very great merit, and a man of great popularity among his colleagues.

\section{Pathogenesis}

Before passing on to the more detailed consideration of my subject, it might be well to refer briefly to certain aspects of the pathogenesis of the disease and its direct bearing on the subject of this address.

It is generally accepted that the $M$. leprae is the causative organism of the disease but owing to the fact that it is a very lowly pathogen, probably having to pass through neural tissue (Schwann cells), before it becomes pathogenic, certain questions have arisen in the mind of many investigators during the last fifty or more years as to just what part the $M$. leprae plays in the picture of the disease.

The reason why certain early workers expressed doubts as to the $M$. leprae being the cause of leprosy is explained, if while not denying the presence and initial cause of leprosy being the $M$. leprae, we assume that this organism itself is a relatively harmless parasite first invading neural tissues particularly Schwann cells, and then the dermal tissues, and finally parasitizing the whole of the reticuloendothelial system. Its very presence seem to trigger off certain disease processes which precipitate the more serious manifestations and complications of leprosy. For instance, there are serum changes; for example, the presence of cryoprotein and the absence of alpha globulin link leprosy with the autoimmune diseases and collagen disorders, e.g. disseminated lupus erythematosis and rheumatoid arthritis.

The conclusion, therefore, to which one is forced, is that while the $M$. leprae is the causative organism of the disease, it appears to set up side reactions which make this mycobacterial in- 
vader merely an onlooker quite unable to intervene in the disturbances which have been set up; it is rather like the person who throws a match on to dry and arid ground and sets going a forest fire. The match is the original cause, but the forest fire is the effect.

In other words, the presence of the Mycobacterium leprae merely serves to trigger a whole series of chain reactions which renders it rather a passive onlooker in a series of malignant processes for which the organism has been initially responsible. The study of leprosy should be closely linked with the general dermatological approach to disease and particular attention should be paid to its relationship with disorders of collagen, auto-immune processes, particularly in relation to disseminated lupus erythematosis, disorders of pigment such as pigmented nevi, and diseases related to non-specific clinical manifestations should not be overlooked. In addition to this, I note that a genetic approach to dermatological conditions is receiving considerable attention at this annual meeting of the American Academy of Dermatology.

In this preamble to my main subject, I am making a plea for leprosy to be taken out of its splendid isolation, not only in the minds of men, but also from its separateness from the overall medical programme in our universities. This is the reason why I am particularly glad to be able to present to the leading dermatologists in the United States an approach to leprosy which, I hope, will convince them that it is a disease worth studying, not only for its own sake, but because of its impact on the whole field of medicine extending from anthropology, immunology, hypersensitivity, auto-immunization, the collagen disorders through to neural physiology, neuropathology, and the broad spectrum of reaction of the tissues to noxious influences. Therefore, if what I have said is in any way partly true, it is of the utmost importance that dermatologists should be acquainted with the earliest possible signs of leprosy for, as in all medicine, early diagnosis is the first pre-requisite to proper treatment and care of the leprosy patient. Even with our relatively effective remedies, we are still groping in the dark, and it is only in the light of pursuance of fundamental studies of leprosy that we shall begin to find our way to its ultimate eradication.
Before, however, detailing the early signs of the disease, I think it is fair to say that the great majority of persons, including medical men who first have to deal with leprosy, are a little perturbed in mind owing to the traditional fear of the disease, and this fear is very difficult to eradicate from the minds of men although there is no justification for such fears. There are altogether too many contradictory statements in regard to the infectivity or noninfectivity of leprosy. Therefore, it may not be out of place to refer to the fact that leprosy is a disease which is very rarely acquired. In fact, although some people say it is highly infective, other people say that it is not at all infective, and some people say that it is acquired by long and prolonged contact and that children are more susceptible than adults, others deny this; therefore, it may be of importance to call attention to these apparently contradictory statements, for in each of these statements, opposite though they may be, there is a very large element of truth. The truth is based on the fact that leprosy is a disease which is closely related to genetic susceptibility.

\section{Early diagnosis of leprosy}

As in leprosy, so in all diseases, the most important step is to diagnose the condition early. When I was a student we diagnosed early tuberculosis by means of the stethoscope. Nowadays, while the stethoscope is still a most useful instrument for the physician, no physician would attempt to diagnose early tuberculosis by this means. Today leprosy is in the same position that tuberculosis was 30 years ago, and the diagnosis of leprosy is always, or almost always, made too late and by the time the diagnosis is made, the patient has had the disease a very long time. For instance, the average time between the appearance of the first sign or symptom of leprosy in a patient and his treatment and diagnosis at Carville is seven years, and it may be as long as 20 years. This in itself underlines the importance that all physicians, particularly dermatologists, should be alerted to the very earliest evidence of the disease. If leprosy is diagnosed at the very earliest stage, then I am convinced it becomes a mere incident in a person's life, but if the diagnosis is delayed, then there is a danger of the disease becoming serious, crippling and deforming, because of the secondary effects produced by the $M$. leprae parasitizing the whole of the reticuleondothelial 
I 'Little abnormal to be seen underneath the epidermis or in the corium. There is some evidence of hyperkeratosis histopathologically but there was little evidence of this clinically'. (X200)

2 A Fite stain of the same section showing a nerve cut transversely deep in the corium, acid-f ast bacilli were seen only in nerves, otherwise there were no acid-fast bacilli either in the superficial or the deep parts of the corium. (Xgoo)

3 Lesions of indeterminate leprosy. Note the hypopigmented lesion in the right loin and another one at about the level of the fourth dorsal vertebra on the same side. The characteristic hypo-pigmentation and clearly defined edge is sufficient for those with experience to diagnose leprosy, but loss of tactile sensation (cotton wool) would confirm the diagnosis. On biopsy, careful search of serial sections might reveal an occasional bacillus, or group of bacilli, in a nerve in the corium.
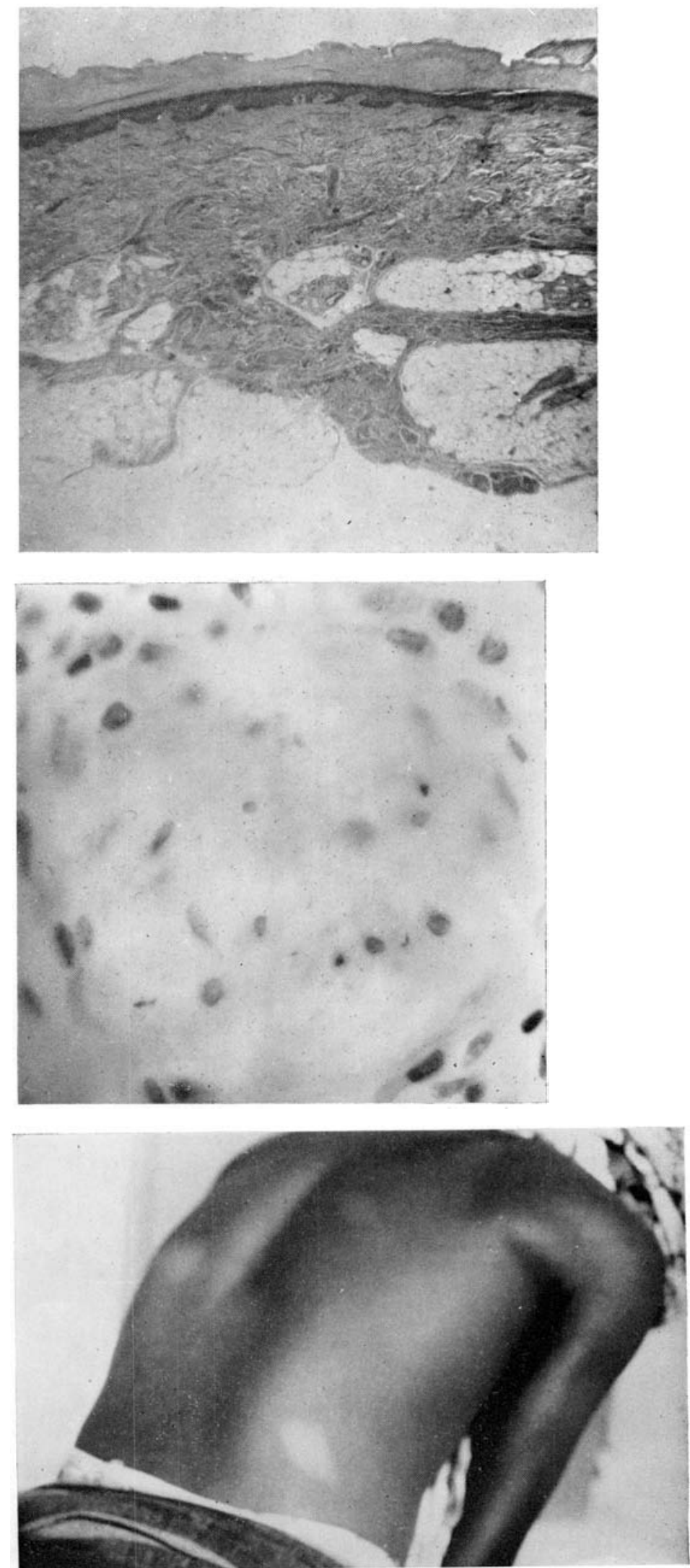

culoid macular leprosy). Note the clearly delineated lesion on the left cheek and forehead - this is an area which is not infrequently the primary site of infection in Africa, where mothers carry their children on their backs. There is also a maculo-anaesthetic lesion on the chin towards the left; there was no lesion on the right side of the face or elsewhere on the body, illustrating the asymmetrical tendency in maculo-anaesthetic leprosy.
4 Maculo-anaesthetic leprosy. (Pre-tuber-

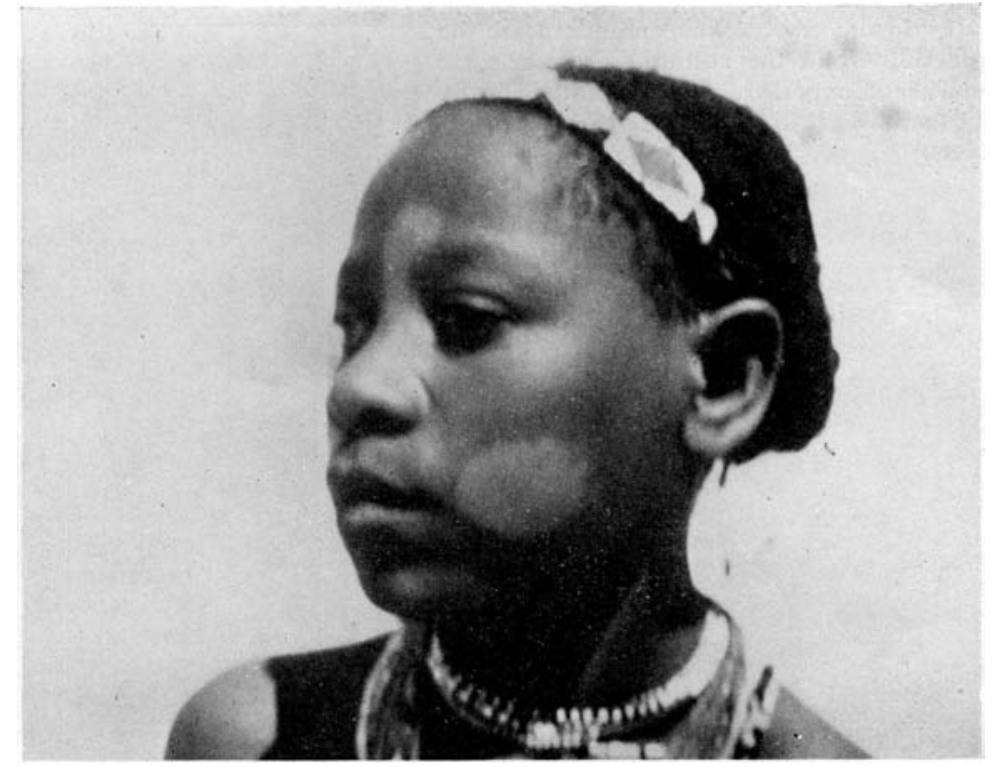

5 A histopatholgical picture of a classical maculo-anaesthetic lesion (pre-tuberculoid). Note the well marked lymphocytic infiltration around the skin appendages, also the area commencing epithelial cell formation at the base of the hair follicle with its well marked peripheral lymphocytic response. (X200)
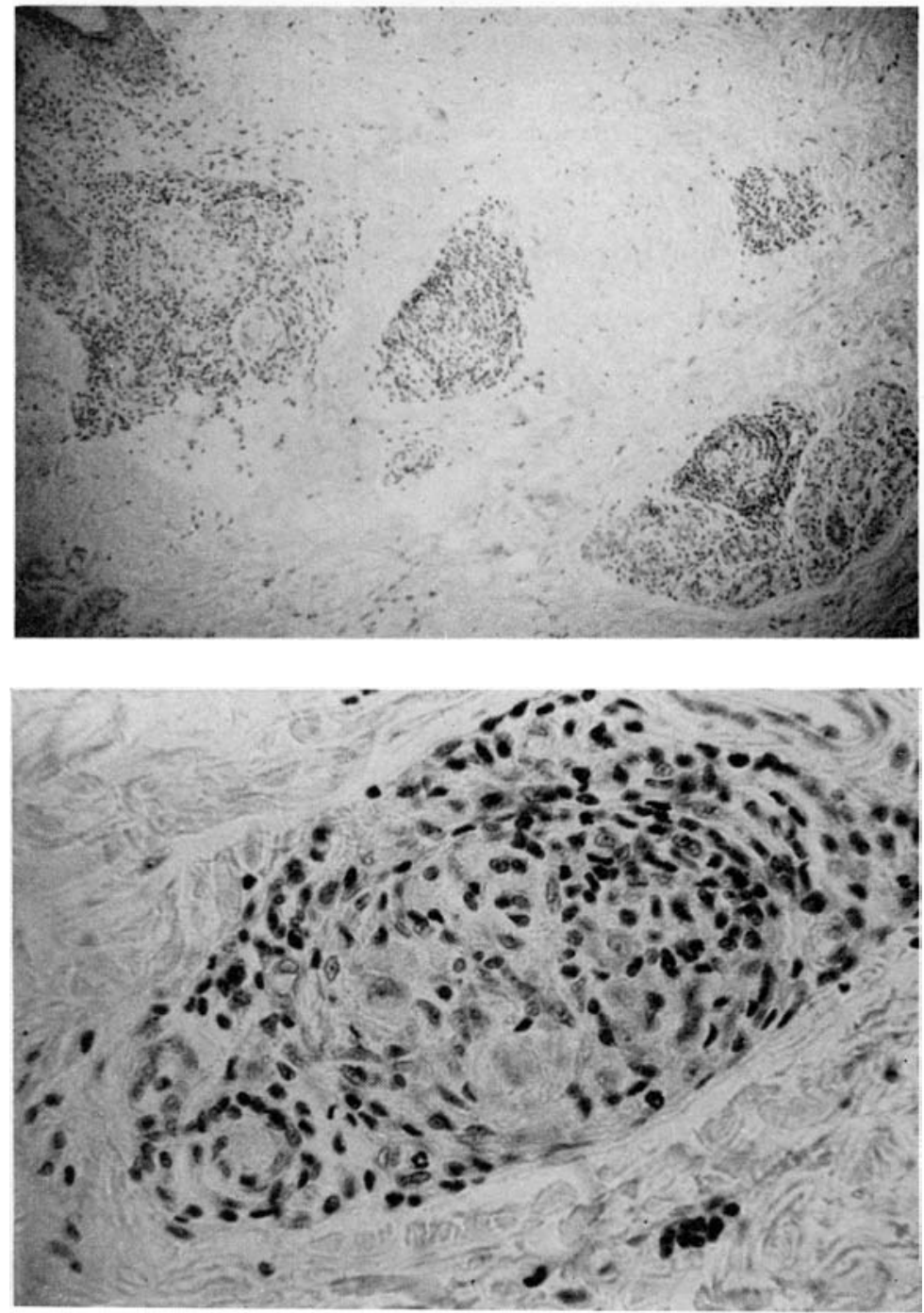

6 Photomicrograph of a nerve in the deeper part of the dermis of the same section as Illustration No. 5. Note the gross involvement of the nerve with epithelioid cells and the concentration of lymphocytes around the periphery of the nerve. The nerve is completely invaded by epithelioid cells and lymphocytes in a characteristic manner, hence the name pre-tuberculoid. This is a tuberculoid focus within a nerve. $\left(\mathrm{X}_{5} \mathrm{Oo}\right)$ 
7 Pre-lepromaious macular leprosy. Note the numerous scattered macules all over the back, buttocks, and the arms, characteristic of this sub-type of lepromatous leprosy, showing very vague indefinite edges, symmetrical distribution and involving the whole of the surface of the trunk, buttocks and extrcmities.
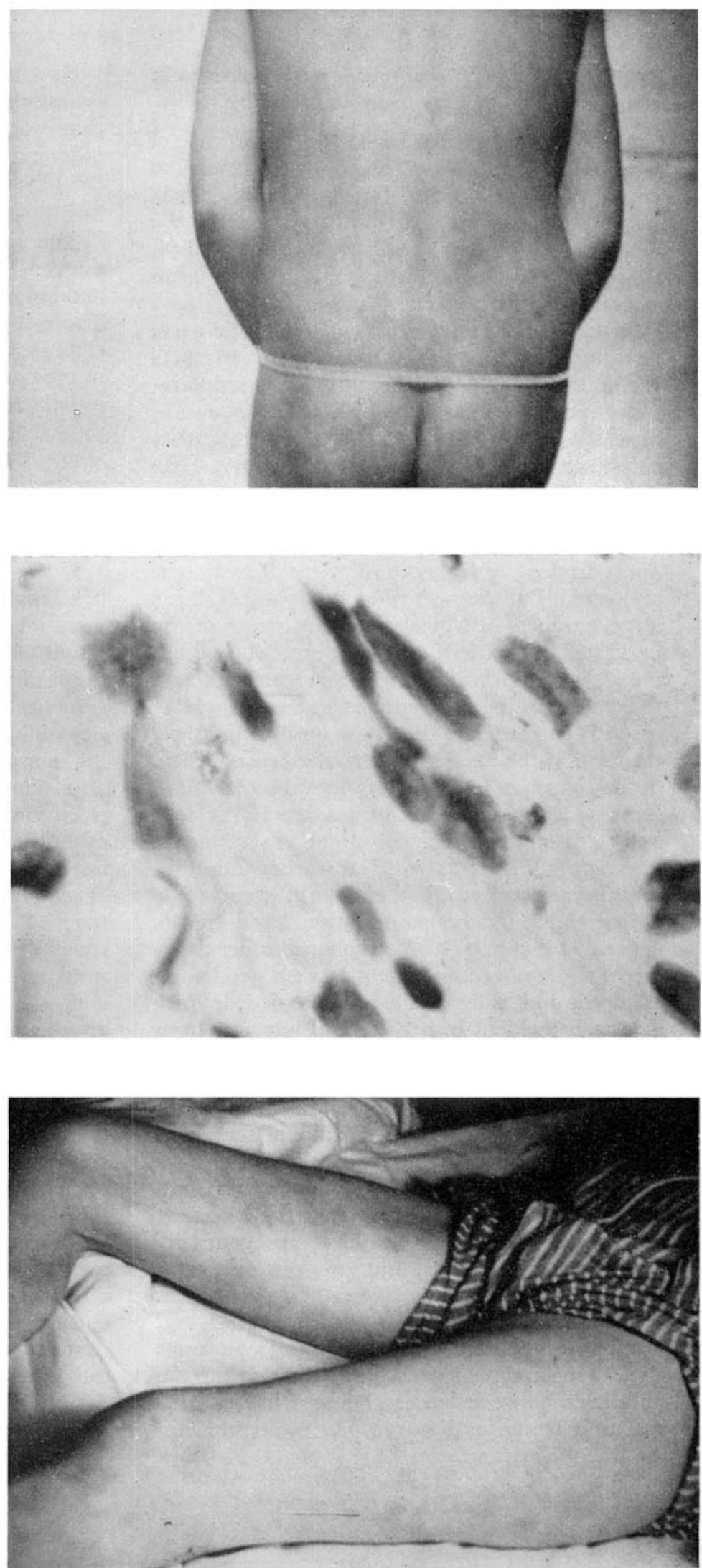

9 Macular lepromatous leprosy. This is a further development from the pre-lepromatous phase in which the macules are much more definite and recognizable but still bear the same essential clinical features - multiplicity, symmetry and vagueness of the edge of the macule.
8 Photomicrograph of a nerve deep in the dermis in a pre-lepromatous lesion. Note the enlarged Schwann cells and the bacilli within the nerve. It is not possible, apart from electron ercopy to say just where the bacilli lie. Some appear to be in the nerve (the axis cylinders), others are so close to the Schwann cells that it is almost certain they are within the cytoplasm of these cells. (X9oo) 
system of the body, and setting up conditions in the nerves which lead to gross crippling.

I have already emphasized the importance of neural tissue in leprosy, and I do not mean to enlarge on this subject, but it has been fairly conclusively shown that the target cell of the Mycobacterium leprae is the Schwann cell and, therefore, the first indication of leprosy is an affection of the peripheral nerves and it shows itself in the form of a numb or anesthetic area. It cannot be too often underlined that any person coming into a doctor's office and complaining of an anesthetic area, or a patch of numbness, should be investigated thoroughly lest he misses very early evidence of leprosy. The following illustrations will show the importance of making the diagnosis at this stage. The first is a photomicrograph of the skin which shows, apart from a little keratosis, very little that is abnormal. But the next photomicrograph shows large numbers of Mycobacterium leprae in the nerves of this patient. This patient, when diagnosed, was a girl of about Io or I I years of age, the contact being the mother who was a nodular case of leprosy. The daughter on examination, revealed at the base of the first metacarpal bone of the right hand an area of slight discoloration, showing less pigment than the surrounding area and with evidence of very slight loss of tactile sensation. The Resident was rather doubtful that there was anything there at all, so we took a biopsy and found, on examination, bacilli in the nerves. This young child was placed under treatment. She is now a woman of 22 with two bonny children, and as far as she is concerned, leprosy is just an incident in her life and has now been completely forgotten. In another instance, a missionary working in Africa wrote to me and said that he had an anesthetic area. I asked for a biopsy, and after about six hours searching serial sections, I came across twelve bacilli in a nerve. That is the time to diagnose leprosy, and if one misses a diagnosis at that stage, the next visible symptoms may be what are generally considered early signs, but are certainly not, that is the appearance of erythema nodosum lesions, with beginning of loss of eyebrows and stuffiness of the nose. These signs and symptoms always mean late leprosy and may mean the difference between leprosy being a lifelong disease and being, as I say, a passing incident in the life of a patient.
Now to turn to the more overt signs and symptoms of leprosy. While leprosy is more of ten than not missed in these early stages, there are other evidences of the disease which should alert the physician to the possibility of leprosy being diagnosed.

The signs and symptoms of leprosy can be divided into macular lesions, infiltrated lesions, and lesions associated with the peripheral nerves. There is one thing in common in regard to all of these visible evidences of the disease; that is in every case the clinical picture can be divided into those who show an exquisite tissue resistance, those who show no tissue resistance, and those who show a partial tissue resistance and on the proper interpretation of the tissue response depends the successful treatment and management of leprosy.

If the earliest sign of leprosy, almost in the preclinical phase, is to be diagnosed, it is essential that physicians should test for tactile sensation very carefully. Too often is the diagnosis of leprosy rejected because there is no evidence of loss of sensation using a pin. It must be emphasized, as all undoubtedly realize, testing sensation by a pin is not eleciting tactile sensation. It is eliciting light pressure and pain sensation, therefore, the only way to elicit loss of tactile sensation is to use a very light touch; for instance, a camel hair brush or a feather, or simply a small wisp of cotton - in Britain we refer to this as cotton wool. It also must be remembered, particularly in children, the patient must know exactly what the physician is doing and there must be very great patience in approaching a patient in the attempt to elicit the loss of tactile sensation. Even the youngest child will respond quite adequately, and sometimes the more sophisticated and intelligent the person is, the more difficult is it to get an adequate response. Where children are concerned it is very essential, as you all will realize, that the child must not be frightened and the best way to approach a child in respect to testing tactile sensibility is to play what I call 'a game of tickles'. Once one has got the confidence of a child, one very seldom finds any difficulty in eliciting loss of tactile sensation. This applies to the American, the British, the French, the African, the Chinese and the Indian child. They all respond perfectly well once a friendship is established between the little patient and the 
Io Characteristic histopathology of the early lepromatous macule. Note the scattered histiocytic and lymphocytic infiltration underneath the epidermis, leaving a relatively clear subepidermal zone. (X200)
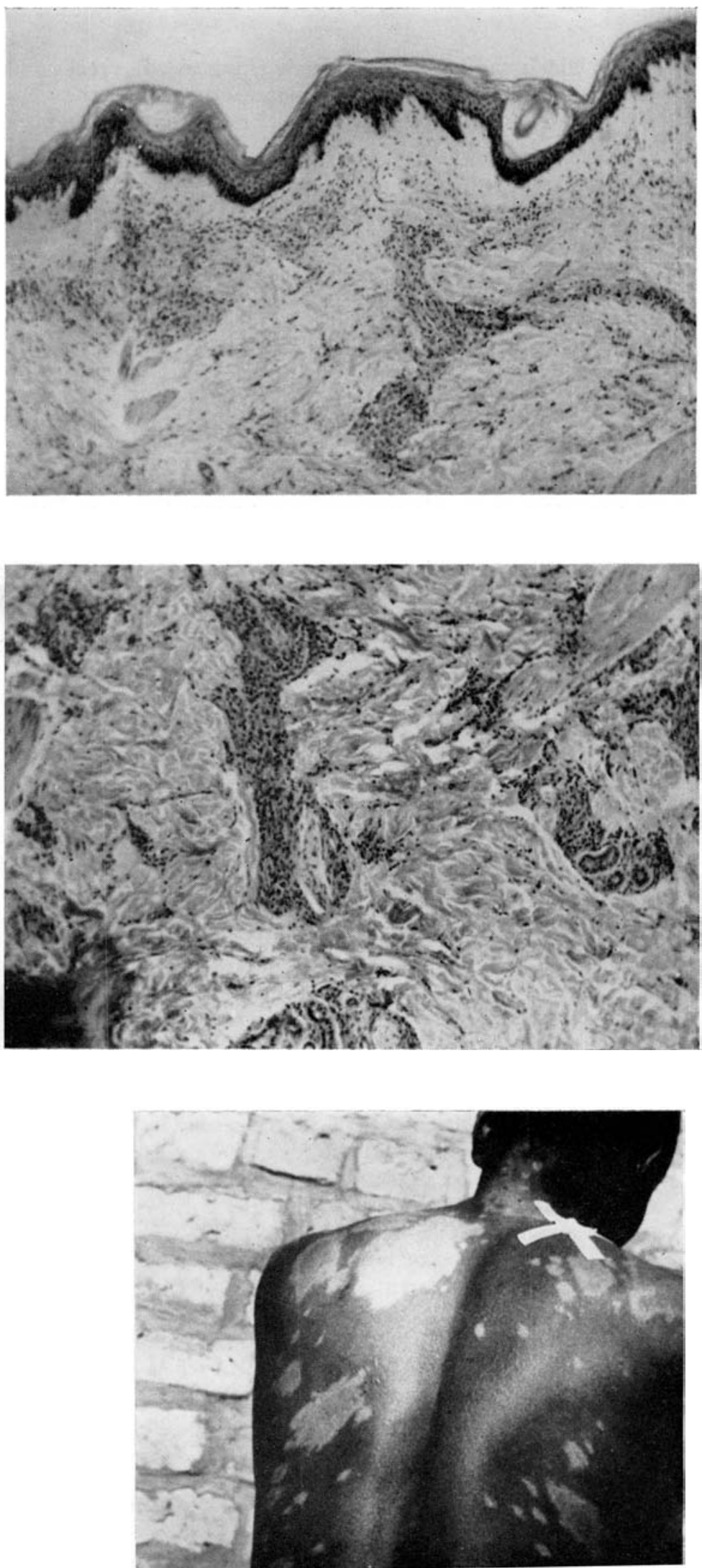

I 2 Dimorphous macular leprosy (sometimes called inderterminate leprosy). Note the multiplicity of the macular lesions, also that in the region of the scapulae the lesions have the appearance of maculo-anaesthetic leprosy in that they are large, with clear-cut edges. On the other hand, between the larger lesions and scattered all over the back are numerous small lesions with indefinite edges. The larger lesions represent the tuberculoid aspect of the dimorphous spectrum, whereas the small multiple macules illustrate the lepromatous aspect.
I I Photomicrograph of the same lesion deeper in the dermis. Note the histiocytic and lymphocytic infiltration around the skin aping out. Schwann cells. (X200) 
physician. It cannot be too strongly emphasized that taking a nasal smear does not necessarily establish a diagnosis of leprosy.

The finding of Mycobacterium leprae in the nasal mucosa is never, and I repeat, never one of the first evidences of the disease. Because of the numerous acid-fast and partially acid-fast contaminants in the nasal mucous membrane, to diagnose leprosy from such a smear is not only highly dangerous but extremely disturbing to the patient.

\section{The diagnosis of leprosy must never be lightly made}

To turn to the clinical and histopathological evidence of leprosy in the macular phase, I would emphasizc first that the very early macule is sometimes extremely difficult to diagnose. No examination should be complete without a biopsy. The following illustration shows a very early macular lesion of leprosy. A diagnosis could not be made except on clinical and histopathological evidence, and unless $M$. leprae were found, or there was early histologic changes suggestive of leprosy the lesion would have to be classified as 'suspicious' and the patient carefully watched. From this indeterminate macular phase, there are three lines of development. One, progress towards the development of an adequate tissue response; secondly, towards the development of an ineffective or absent tissue response; and, thirdly, towards the development of a partially effective tissue response. These three varieties of macular lesions are often described as maculo-anesthetic (pre-tuberculoid), prelepromatous and macular leprosy, and dimorphous (sometimes referred to incorrectly as indeterminate) macular leprosy. The next illustration shows the maculo-anesthetic lesion. Note the lesions on the face are well marked and clear cut and, while superficial tactile sensation is very difficult to elicit on the face, there was some evidence of loss of tactile sensation. But, on careful examination of such macules histopathologically, one is able to show that the essential tissues response is one of a commencing adequate tissue resistance, or the beginning of the evidence of a tuberculoid lesion and the next illustrations show the histopathology of one such lesion. Note the concentration of the lymphocytic and histiocytic response around the skin appendages and neuro-vascular bundles. Note the commencing attempting at forming epithelioid cells and, lastly, note the evidence of invasion of the nerves in the subcutaneous tissue showing the presence of epithelioid cells and one multinucleated epithelioid cell, establishing the diagnosis of leprosy.

The next illustration shows that form of leprosy in which there is absolutely no tissue response. There are multiple small macules scattered all over the body, on the front and back, and the trunk, almost impossible to recognize unless the patient, usually a child, is taken out into the sunlight or placed in a room with excellent artificial light. The bright light is directed obliquely onto the patient's back and then the small multiple erythematous macules stand out like little pieces of quartz shining in the sun. There is very little evidence of any loss of tactile sensation in the macules, but frequently if caref ully tested, tactile sensation will be found to be diminished along the ulnar border of one or other hand or hands, or the outer border of the foot showing that both the ulnar and the common peroneal nerves are affected. Diagnosis is confirmed by the histopathological appearance of the lesions which in the earlier lesions show a non-specific inflammatory response, but bacilli are seen in the nerves and in the dermis; and in the later macular phases the histology is that of a moderate histiocytic and lymphocytic infiltration underneath the epidermis leaving a clear sub-epidermal zone. In the dermis proper, there is also a lymphocytic and histiocytic response, but note the nerves are very clear and are easily recognizable and within the dermis there are masses of acid-fast bacilli. These early lesions represent that form of macular leprosy in which there is no tissue response. I should add here that the lepromin test is not diagnostic, it only indicates the actual or potential presence or absence of tissue resistance in an individual. When the early lepromatous macular lesions begin to develop, then the characteristic macular appearance of leprosy is seen. The following is an illustration of early macular leprosy. Note the widespread distribution of the lesions, the very vague edge and a general erythema. In the dark skin, these lesions are much more difficult to recognize than in the light skin. But in the light skin, they are more ofter misdiagnosed for macular lesions due to allergic factors, erythema multiforme, or some other erythematous dermatologic condition which a dermatologist may see in his

I 96 Leprosy Review 
13 Photomicrograph of a dimorphous macular lesion. Note the lymphocytic and histiocytic infiltration tends to be concentrated around the skin appendages and vascular bundles. Also note that the infiltrate does not go up to the epidermis but tends to leave a relatively free sub-epidermal zone. ( $\mathrm{X}_{\mathrm{IOO}}$ )

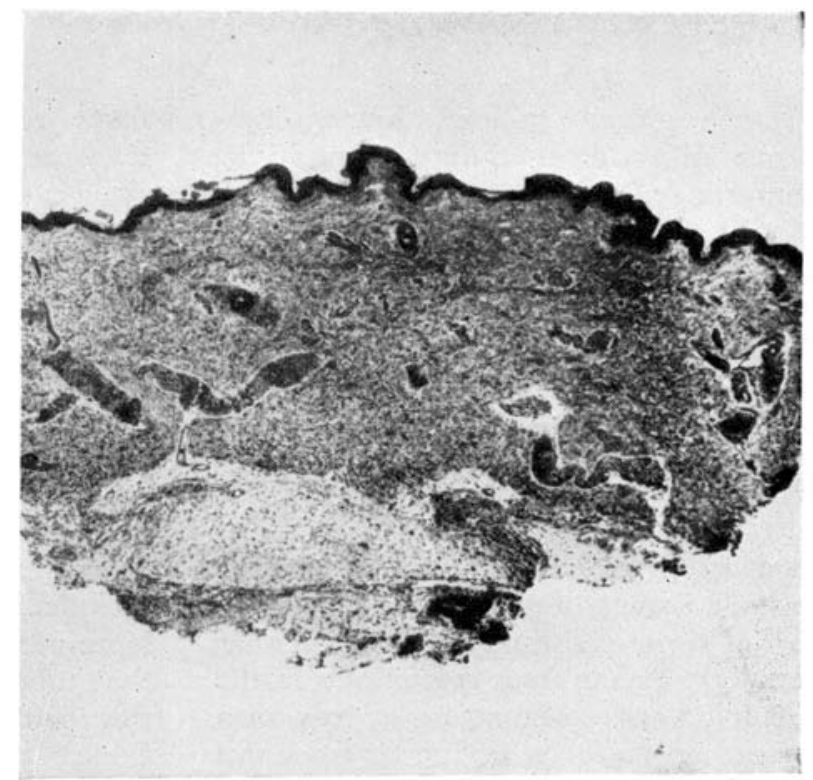

I4 Photomicrograph of an area of the same section showing a well marked lymphocytic focus in the region of a neurovascular bundle. Note the intense accumulation of lymphocytes and a small nerve which shows no involvement stands out clearly, indicative of the lepromatous aspect of the dimorphous lesion. (X200)

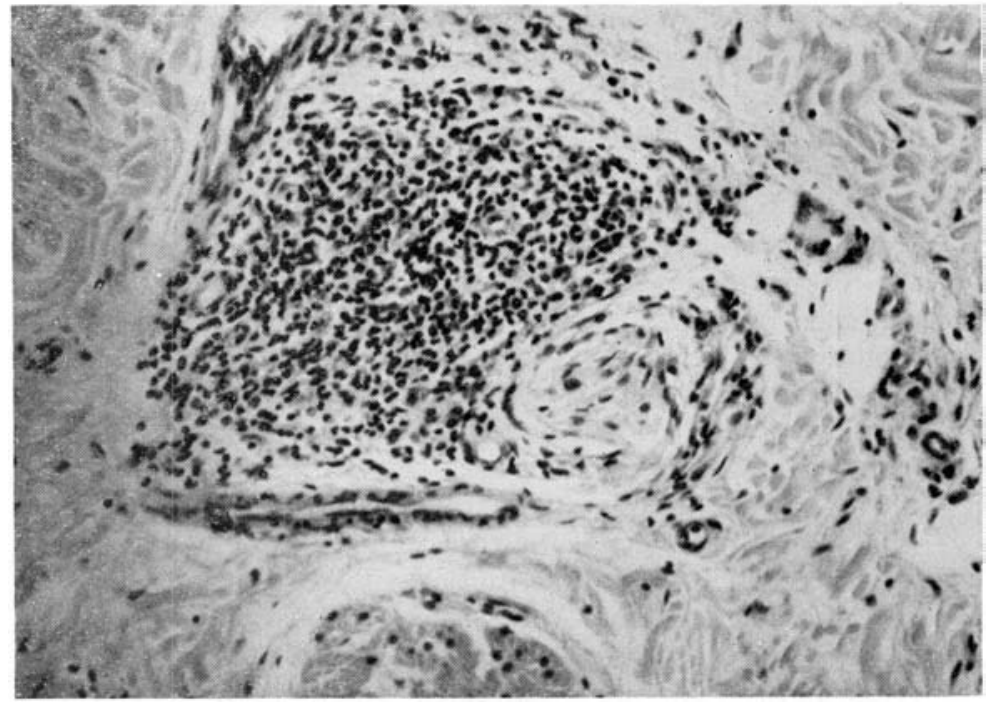

I 5 This is a photomicrograph of the same section deep in the dermis. A long band of infiltration represents an area in the vicinity of a group of sweat glands. On the right there is an elliptical shaped structure which shows gross involvement with lymphocytes and histiocytes. This is the remnant of a nerve. On the left in the area of a blood vessel is another small nerve, again elliptical in shape. This shows much less involvement, nevertheless it is also partially invaded. In other words the nerves in this area are very difficult to recognize, and almost completely involved with a cellular infiltrate, lymphocytic and histiocytic, but there is little or no evidence of epithelioid cell formation. The infiltrate then in this area shows destruction and distortion of nerves and, therefore, represents the tuberculoid element of the dimorphous zone. Therefore, histopathologically and clinically, there are tuberculoid as well as lepromatous responses in this nerve, and in addition the nerve showed

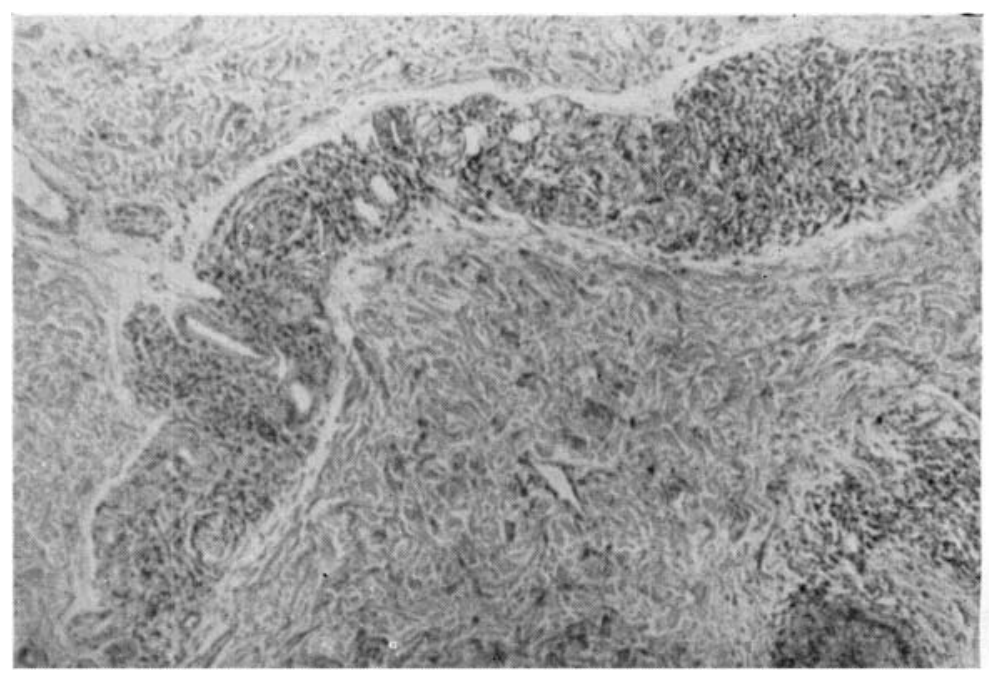


office. Therefore, if any patient, presents himself in your office complaining of multiple, erythematous macular lesions which do not itch and do not fit into standard dermatologic diagnosis, and which do not respond to standard treatment, then remember leprosy and never, and I repeat, never omit a biopsy. When a biopsy is performed, never forget the precaution of having a section stained for acid-fast bacilli. If you do this, you will frequently get surprises, but you will not miss early macular lepromatous leprosy.

With regard to macular lesions of leprosy, there is a third variety of macular lesions which shows partial tissue resistance: that is, neither the potentially exquisite tissue response as in the pre-tuberculoid variety of macular leprosy, or a lack of tissue response as in the lepromatous type. This form of leprosy is sometimes called indeterminate macular leprosy. Dimorphous meaning both forms or shapes of lesions in the one person - tuberculoid and lepromatous, and histopathologically evidences of a partial tissue resistance. The following is an illustration of a classical dimorphous macular case of leprosy. Note that the larger hypopigmented lesions have a clear cut edge, they are large, and there is evidence of loss of tactile sensation and they occur in the areas which are most likely to be pressure points, the scapulae, the buttocks, the outer aspects of the extremities and the face. In between these larger macules, are groups of small macular lesions scattered over the trunk with lack of clearness of the edge. The edges, in fact, are somewhat fuzzy and usually do not show loss of sensation. When these lesions are biopsied and examined, the following is the general histopathologic picture: there is a scattered infiltrate underneath the epidermis with some evidence of a clear sub-epidermal zone. In the dermis, the infiltrate tends to be concentrated around the skin appendages and neurovascular bundles. Some nerves are grossly involved, others are free from infiltration. When an acid-fast section is done, not infrequently Mycobacterium leprae are seen in the nerves and sometimes in the tissues in varying numbers. These, then, are the macular lesions of leprosy and now we pass on to the infiltrated lesions.

\section{Infiltrated lesions}

As in the macular phase of leprosy the lesions can be divided into those which show an exquisite tissue response, those which show no tissue response, and finally, those in whom there is some capability of putting up a tissue resistance of varying degrees. So then in all these lesions which are infiltrated, one sees the same tissue responses except that these are more exaggerated. There is generally a tendency in the Americas because of the paucity of the classical tuberculoid lesion, to place nearly all those lesions which are not lepromatous into the tuberculoid classification. If, however, tuberculoid means that form of the disease in which there is an adequate tissue response, then it is impossible to include all the raised lesions which are not lepromatous in this category. Many persons say that tuberculoid leprosy is a common form on this continent, but on the other hand, the Caucasian and Mongolian races belong to that group of persons, who, generally speaking, are unable to develop an adequate tissue resistance to the $M$. leprae. Also, I think it is fair to say that there are few absolutes in nature. Therefore, it seems logical that the largest group must be among those individuals who show a partial or dimorphous tissue response. It is my belief that the great majority of persons probably fall into the mid-zone, that is the dimorphous or as it is sometimes called, the border-line zone. The reason for this is because nature, as a rule, does not like absolutes.

\section{Tuberculoid leprosy}

Tuberculoid leprosy is a manifestation of an exquisite tissue resistance and I have never personally seen a true tuberculoid case transform into lepromatous when the lesions are studied from the immunologic, histologic, and the clinical point of view. Tuberculoid leprosy then is seen in two sub-types. One, the established tuberculoid lesion and, two, disseminated tuberculoid lesion. Both forms of leprosy have a simliar clinical, immunologic, and histologic picture except that there are some slight variations which indicate that the histopathology and the clinical features are not quite the same. The established tuberculoid lesion is usually seen as a single lesion. If the infiltration is gross, then it is a major tuberculoid lesion. If the infiltration is slight, then it is a minor tuberculoid lesion. The chief characteristics of the lesions are that they occur as single, or not more than two lesions with very clear cut edges. There is absolutely no doubt about the edge of the lesion as is shown in 
I6 A lesion of established tuberculoid leprosy of minor grade. Note the peripheral papulated healing area indicating a centrifugal spread. No biopsy, unfortunately, was performed on this case, but it would have shown well marked and clear-cut epithelioid cell foci, not only immediately underneath the epidermis but in connection with the skin appendages and neurovascular bundles.

I 7 An excellent example of an established tuberculoid lesion. Note the large infiltrating plaque on the left back with clear-cut edges; note also that the lesion is beginning to show spontaneous regression. edge, clear-cut, with a central scarring or
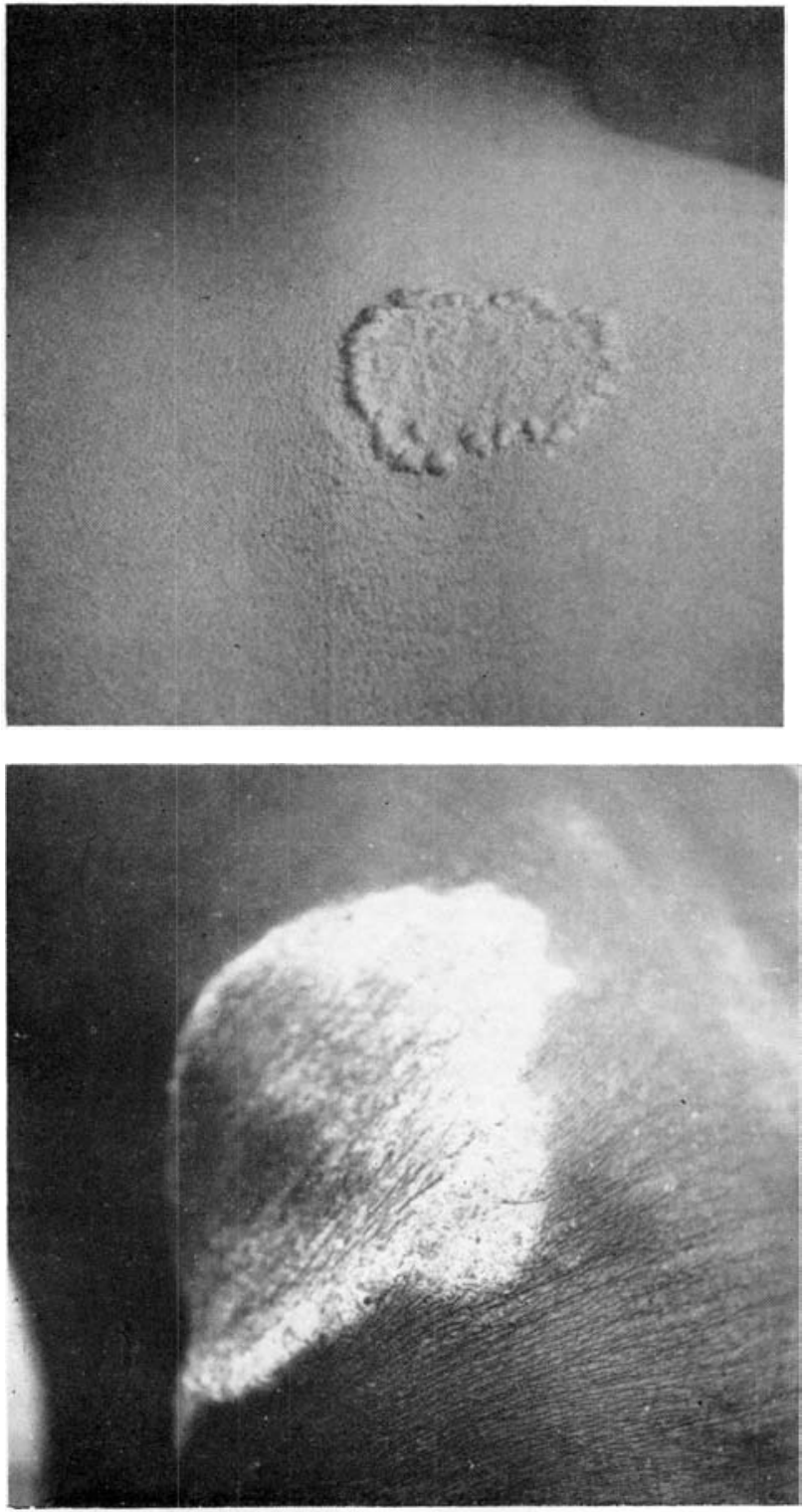

I 8 Photomicrograph of a biopsy from the edge of the same lesion. Note the massive granulomatous infiltration throughout the corium, the infiltrate extends up to the epidermis. There is no evidence whatever of any separation of the infiltrate from the epidermis. In other words the sub-epidermal area is absolutely obliterated. No nerves are recognizable. This gross granulomatous reaction results in the death of the bacilli and healing by scar tissue. In pre-sulphone days these lesions were not treated for when sulphones are used they have to be used extremely carefully and must not be given in the acute reactive phase or else further damage may result. (X200)

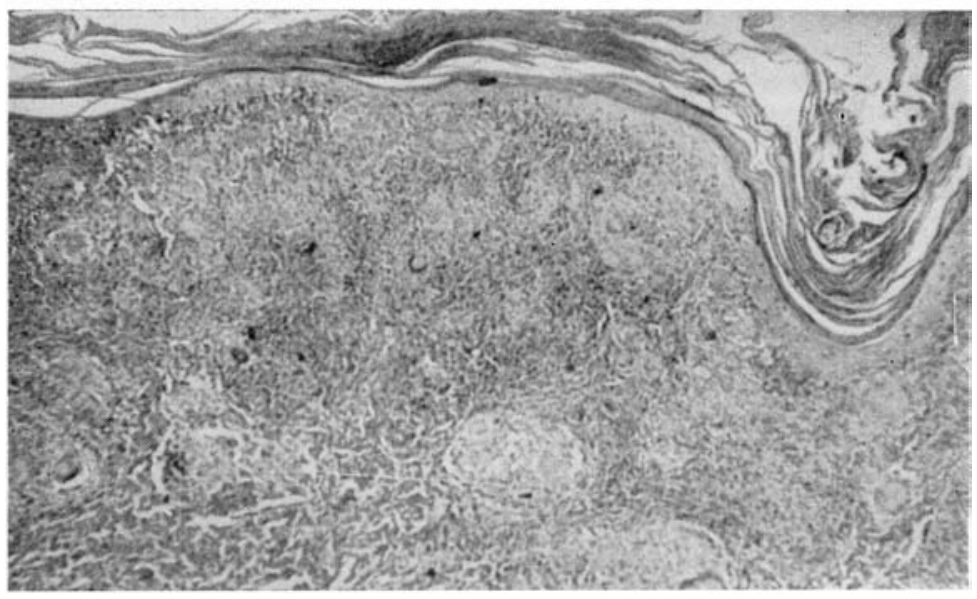


I9 An established major tuberculoid lesion on the face showing an acute reaction which is beginning to subside. Note the ulcerated area and the gradual receding of inflammatory response at the edge of the lesion, also note the compensatory sweating on the left side of the face and the facial paralysis on the right. Had this boy been given a heavy dose of corticosteroids (the equivalent of 300 to $400 \mathrm{mg}$ cortisone a week) the whole of the inflammatory response would have been damped down and the patient would have been saved facial palsy.

20 Diffuse lepromatous leprosy in a member of the Caucasian race. Note the puffiness of the face, the well marked eyebrows and a relatively smooth infiltration with no nodulation or grossly visible infiltrated areas. This form of leprosy is very deceptive for apart from a little puffiness of the face and some vague erythema the patient would not be recognized as having leprosy, although the skin and his nasal secretions would be full of acid-fast bacilli.

2 I A diffuse lepromatous case in an Indian. Note the two white spots on the right back, these are scars of old injuries. Note also in the background of the diffuse lepromatous infiltration are residual macular lesions which, one would assume, were the original dimorphous lesions and all these have now largely coalesced to form a diffuse infiltration throughout the back, in fact throughout the body. Wherever a smear were taken it would be full of acid-fast bacilli. These diffuse lepromatous lesions constitute a considerable hazard, the patient looks well and healthy and only when the physician takes the patient out into the bright sunlight can a greasy, diffuse, lepromatous infiltration of the skin be recognized.
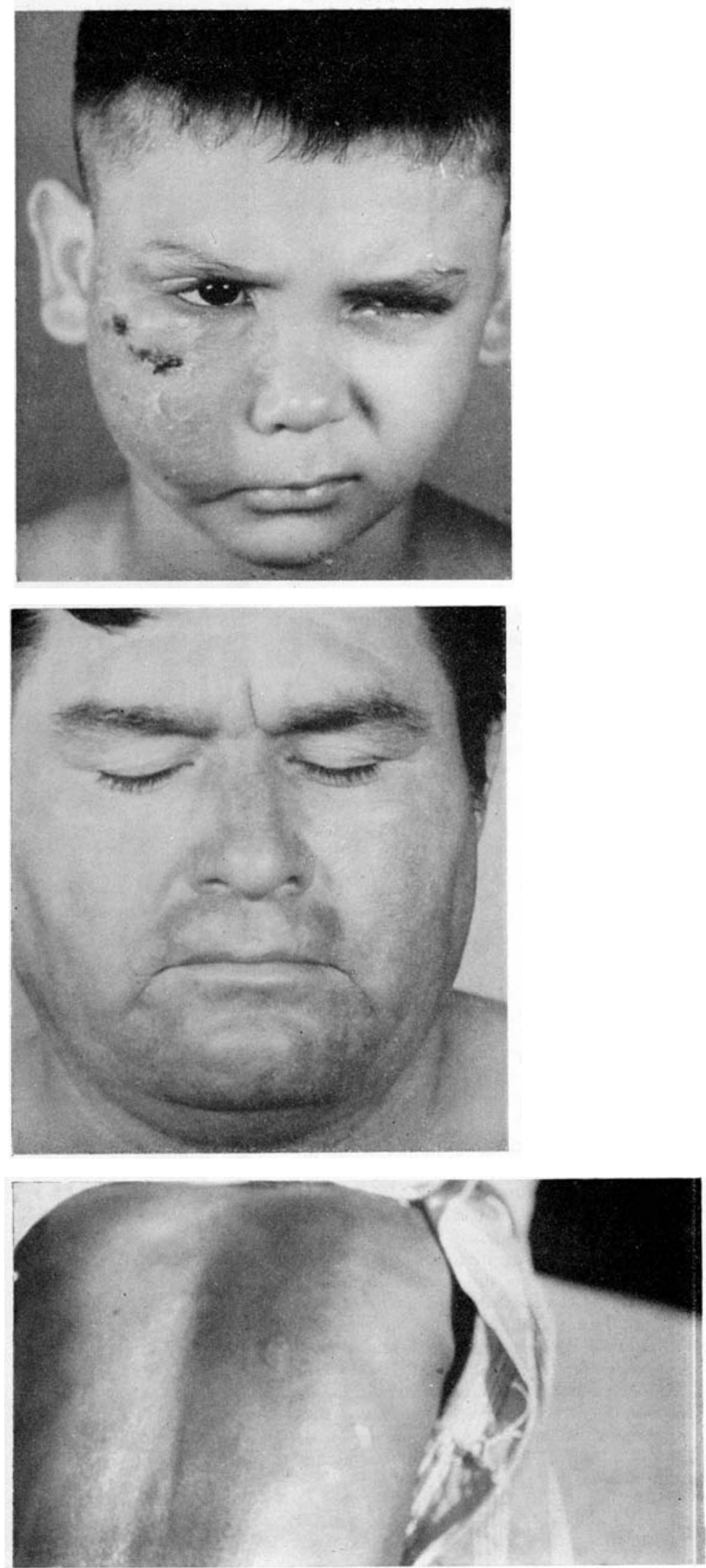
22 A photomicrograph of a diffuse lepromatous leprosy. Note that the whole dermis is occupied by a histiocytic infiltration with here and there scattered lymphocytes. The lymphocytic response is in no way focalised. Note also that the macrophage cells have a bubble appearance, this is characieristic of the early formation Virchow's foam cells. Here and there in the infiltrate are a few plasma cells. In such cases the ratio of serum albumin and serum globulin is reversed. (X2OO)
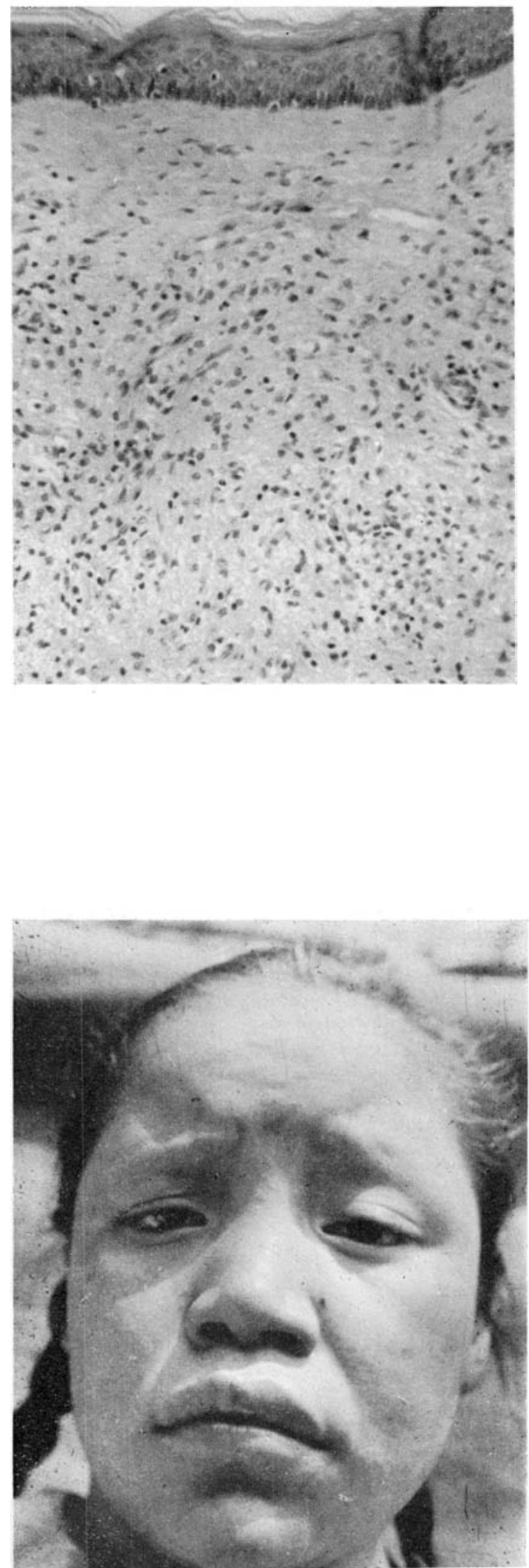

23 Diffuse lepromatosis of Lucio. This is a clinical sub-type of lepromatous leprosy seen almost exclusively in Latin America, particularly in Mexico. It manif ests itself as a dirluse infiltration of the skin with no visible nodules or thickened areas. The patient is frowning and therefore the region of her eyebrows looks infiltrated. Actually the whole face has a smooth, greasy appearance with loss of eyebrows, loss of, or scanty, body hair. (Axillary and pubic). 
24 It is in this sub-type of lepromatous leprosy that the Lucio phenomenon is seen. The lesions start with an erythematous macule which soon becomes purpuric in appearance, then an ulcer forms and breaks down to the scab and shows the beginning of healing. In the days before sulphone therapy such cases usually died of amyloid disease.
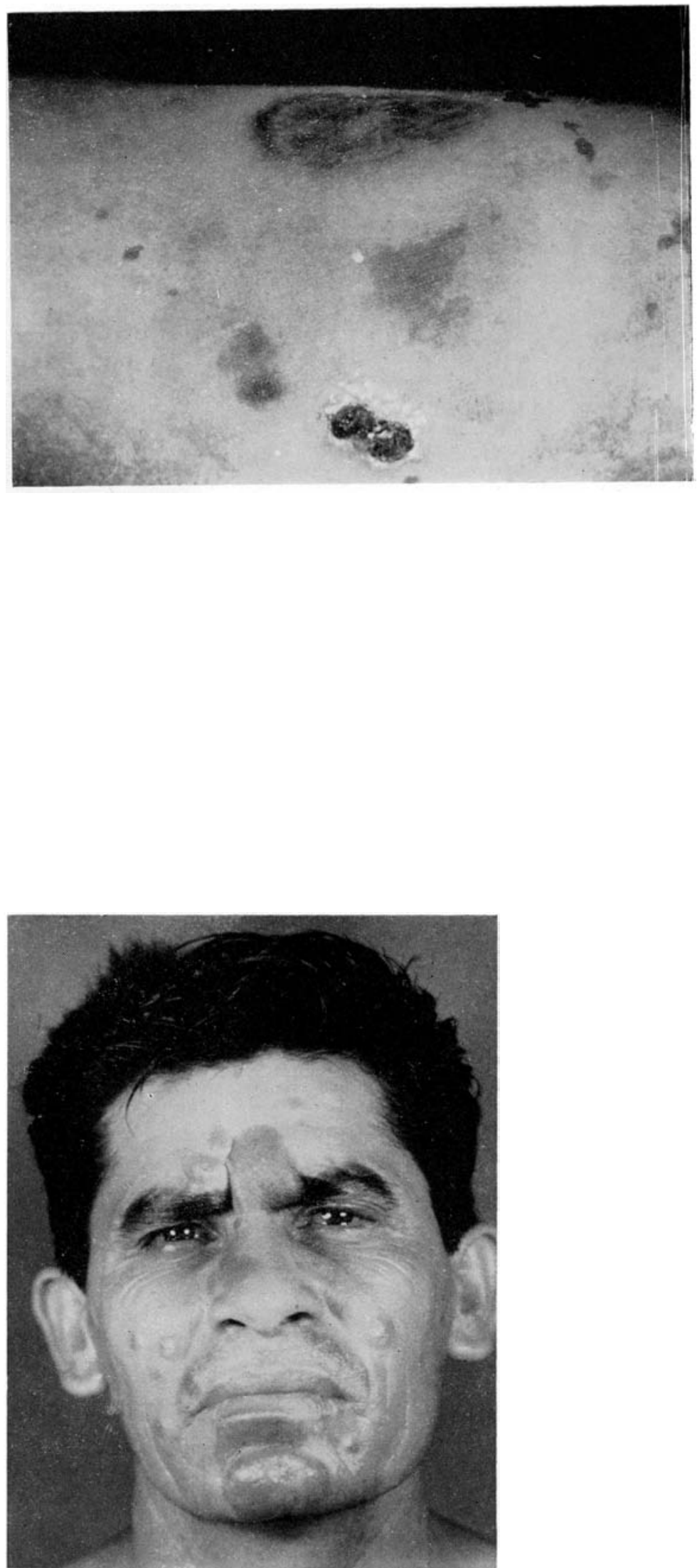

25 Infiltrated dimorphous leprosy on the tuberculoid side of the dimorphous spectrum. Note the relatively clear-cut lesions on the forehead and the characteristic dome shaped lesions on the chin and cheeks, and the widespread and symmetrical distribution of the lesions. 
26 Histopathology of a dimorphous tuberculoid lesion. Note the clear sub-epidermal zone and the well marked epithelioid cell foci in the corium. The answer is a clear subepidermal zone and the lesion then is in the dimorphous zone no matter how 'tuberculoid' the lesion may appear clinically. (X200)

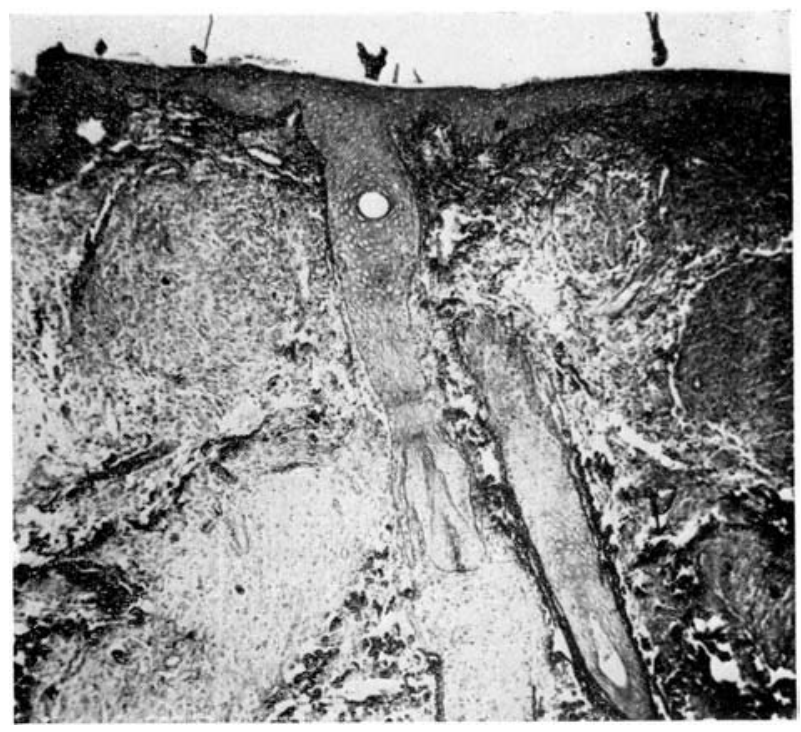

27 Disseminated tuberculoid leprosy. This is a form of tuberculoid leprosy which, clinically, has the appearance of tuberculoid leprosy but the lesions are multiple and disseminated all over the body, in other words, this sub-type of tuberculoid leprosy is spread by the blood stream.

28 The histopathology of disseminated tuberculoid leprosy. Note the partially obliterated sub-epidermal zone, the well marked foci of epithelioid cells with only a moderate lymphocytic response. In other words the focal distribution is not as clearly delineated by a peripheral lymphocytic response as seen in the established tuberculoid sub-type (Compare illustration 18, X200).
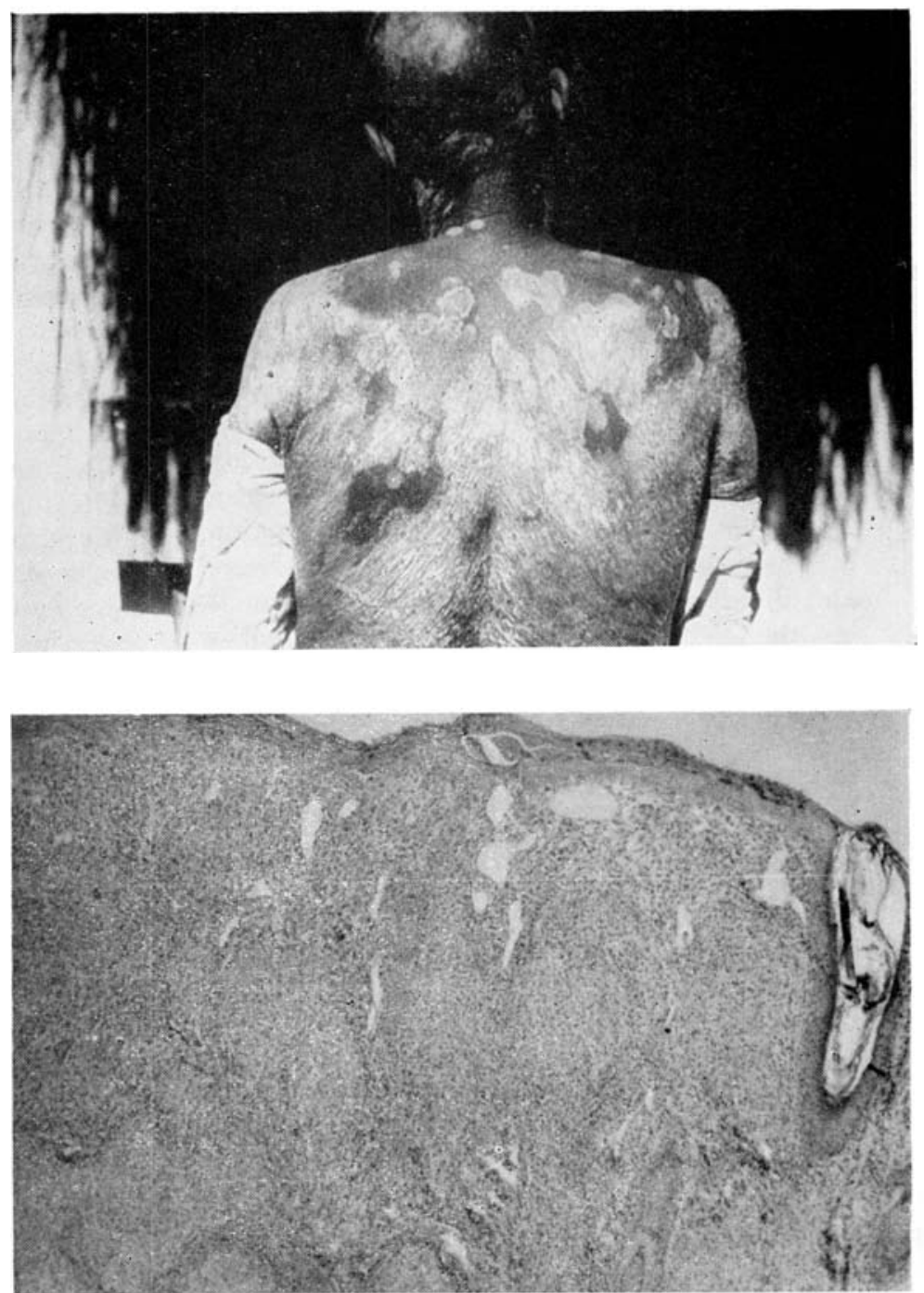
the following illustration. Anesthesia is always present and frequently there is enlargement of the subcutaneous nerve going to the lesion. When such a lesion passes into an acute reaction it has not infrequently been diagnosed as a cellulitis, or even an erysipelas. On careful examination, however, the features of tuberculoid leprosy will be indicated and almost certainly, the superficial cutaneous nerve to the affected area will be found to be enlarged. The following is an example of the type of tuberculoid lesion which could be mistaken for an acute cellulitis. The histopathological picture in such lesions is very definite. There is a gross infiltration occupying the whole of the corium. The sub-epidermal zone is completely blocked, as in this illustration, and this histopathology is also illustrated under the microscope. This form of leprosy, I feel, is probably related to that type of lupus, called lupus verrucosus, in which the infection comes ftom a direct innoculation either through the handling of infected meat or in the rare instance, of direct innoculation of those who are in attendance on patients suffering from 'open' tuberculosis (Ingram and Brain I957). On the other hand, there is a form of tuberculoid leprosy which is disseminated by the blood stream. Instead of a lesion appearing at the place of innoculation, there are multiple lesions throughout the body. In such instances it is quite easy to surmise that if the tissue response is not quite so gross as in the established tuberculoid leprosy, then the occasional bacillus and, especially if the tuberculoid lesions go into reaction, may pass into a lymph node or a blood vessel and the disease becomes disseminated throughout the body. The features of disseminated or low resistant tuberculoid leprosy are very similar to that of the established form, except that the lesions are multiple, they are grossly infiltrated, and the edge is very clear. The following illustrates what I mean by disseminated or low resistant tuberculoid. The histopathologic picture is also illustrated under the microscope and in the photomicrographs I have set out. The main feature of the histopathology of this lesion is that, while there is a gross infiltrate occupying the shole of the dermis going up to the epidermis, but here and there, there is a looseness of the infiltration separating the granulomatous tissue in parts from the epidermis. In addition to this, there is a tendency for the lymphocytic element to be less manifest and the epithelioid cell reaction is in greater evidence.

\section{Lepromatous leprosy}

This is that form of leprosy which is placed at the other polar end of the spectrum, and it is seen in those infiltrated lesions which show no tissue response whatever. The tissues are anergic to the presence of the Mycobacterium leprae. There are two sub-types of infiltrated lepromatous leprosy; namely, diffuse lepromatous leprosy and grossly infiltrated, or nodular leprosy. I do not propose to describe the latter variety of leprosy because it is too well known to need any description, but the diffuse lepromatouse case of leprosy is of extreme importance to physicians and particularly to dermatologists because these lesions are very diffiult to recognize, and it needs a trained eye to be certain that one does not miss this potentially dangerous subtype of leprosy because the tissue response is so ineffective that the actual lesions are not seen. Diffuse lepromatous leprosy then manifests itself by a diffuse infiltration of the whole skin. The infiltration is felt rather than seen. If one picks up the skin between one's fingers one appreciates the generalized infiltration of the dermal tissues. These diffuse lepromatous cases are difficult to diagnose if one is not alerted to the condition. The following are examples of diffuse lepromatous leprosy.

Diffuse lepromatous leprosy is diagnosed by feel rather than by sight, because it is a diffuse infiltration of all the skin. The patient himself frequently does not feel ill, although there may be some nausea and slight increase in temperature when he goes into a reactive phase; but normally he can play games, build houses, hew down trees, and indulge in normal activities. Nevertheless, if a biopsy is taken of one such patient, there is usually found a large number of acidfast bacilli. It is important, therefore, for practitioners to remember that this condition is very easily overlooked and if there is any cause to suspect that the patient has been in an endemic area of leprosy, then the simple precaution should be taken of taking smears from the ear, from the forehead, and if possible from the buttocks which would reveal at once the presence or absence of diffuse lepromatous leprosy. The only outward visible sign is a slight greasy-looking appearance of the skin, some change in the 
eyebrows and nothing indicating any specific dermatological condition of the skin. There is no evidence of anesthesia except perhaps some numbness in the outer aspects of the hand (ulnar distribution), outer aspects of the foot (common peroneal distribution). It might be well to emphasize at this point that taking a nasal smear may not necessarily give the diagnosis for in early diffuse lepromatous leprosy, the nasal lesions may not be positive to routine methods of examination and, therefore, nasal smears should not be relied upon as a mode of confirming one's diagnosis. Histopathologically, there is diffuse infiltration throughout the dermis leaving a clear sub-epidermal zone. The infiltrate consists mainly of histiocytes of the large macrophage variety many of which show characteristic foamy cell change. In addition to this, the nerves are very well seen and when the section is stained by the Fite technique, acid-fast bacilli are seen throughout the dermis and the nerves.

This form of diffuse lepromatous leprosy must not be confused with the diffuse lepromatosis of the Lucio type. This form of diffuse lepromatous leprosy appears to occur only in the Latin American continent, particularly Mexico. Here, again, the skin has a diffuse greasy appearance and the infiltration is felt rather than seen, but in addition to this, there is gross loss of eyebrows, eyelashes, and body hair and it is in this type of diffuse lepromatous leprosy that the characteristic Lucio phenomenon appears which is a reactive phase of lepromatous leprosy. In fact, erythema modosum, panniculitis nodosa, and Lucio leprosy are all of a similar pathologic nature. Lucio leprosy is the most severe of all these forms and is seen as an obliterative endarteritis giving rise to the characteristic Lucio ulcer which occurs usually on the extremities, and was extremely difficult to treat, but now that we have sulfone therapy these lesions have largely lost their terror.

I have now reviewed the main features of lepromatous leprosy and I do not think that it is necessary for me to detail the clinical signs and symptoms of advanced infiltrated nodular leprosy for by the time a patient has reached this stage of advancement the disease should be easy of diagnosis.

I will now pass on to that form of leprosy which is described as infiltrated dimorphous or borderline leprosy. These clinical manifestations show themselves in lesions which have somewhat the appearance of an effective tissue response, i.e. tuberculoid leprosy, and lesions which simulate the general picture of lepramatous leprosy. It is in this area of the spectrum that considerable confusion arises in many person's minds. In I 936, Dr Wade styled this form of leprosy as 'borderline' while Lowe referred to those cases which were not definite tuberculoid or lepramatous as ' $\mathrm{N}$ ? P'. In those days we divided leprosy into neural and cutaneous types. Just as the histopathologic picture is varied, so is the clinical for this is a very broad spectral band. Some lesions are very similar to tuberculoid lesions, whereas others are nearer to the lepromatous classification. It is because this zone is merely a part of the total spectrum of leprosy that one has designated it the dimorphous zone. The best way to describe the varied picture of this sub-group is by showing illustrated Kodachromes depicting the various clinical lesions. One thing one must bear in mind is that clinically the lesion may show well-marked infiltration, they may be plaque-like, but the edge of the lesion is never clear-cut and one has to look at the lesion and try and determine the most prominent part of that lesion. If the most prominent part of the lesion is away from the edge, even though it is iust inside the edge, then the lesion histologically nor clinically nor immunologically is a true tuberculoid lesion. The importance of recognizing this dimorphous picture is because these are the most unstable of all clinical forms of leprosy and they have to be treated with the utmost caution.

In conclusion, Mr President, I have to remind this distinguished audience that the diagnosis of leprosy is relatively simple if it is remembered that the first presenting sign of the disease is anesthesia or numbness; also the physician must always be alert to the fact that any lesion which is slightly bizarre and does not fit into a standard dermatological diagnosis, leprosy must be ruled out before a firm diagnosis is made. Furthermore, the importance of recognizing the various tissue responses to the challenge of $M$. leprae cannot be too greatly stressed, for to place a lesion in the wrong classification may give rise to serious damage and mis-management of the whole treatment of the individual. It is sometimes the best policy not to treat at all. Also, in relation to the diagnosis of leprosy with special 
reference to tissue response, there are certain forms of leprosy which are extremely unstable and the standard treatment of DDS or Dapsone may have to be withheld for a considerable time. Finally, it must be borne in mind that treatment is not easy and requires patience, persistence and time in order to overcome those numerous side effects which the presence of the Mycobacterium leprae triggers. Unless this is understood the diagnosis and management of a case of leprosy may end in, if not a disaster, very serious consequences to the patient in the nature of deformity and produce a psychological state of utter despair.

Furthermore, if it is true that the Mycobacterium leprae triggers off certain side reactions which are related to the auto-immune processes and to the collagen diseases, then one must be very cautious before administering corticosteroids. If they are administered they must be given in very small dosages. It has been shown that corticosteroids because of their ability to inhibit or depress lysosome activity frequently are responsible for the patient passing into a stage where, humanly speaking, the prognosis is hopeless.

I, once again, would emphasize very strongly that the initial symptom or sign of leprosy is numbness or anesthesia. If leprosy is diagnosed at this stage, then it may mean the difference between leprosy being merely a passing incident in life or years of agonizing failure ending in despair, deformity, and death.

Thank you, Mr President, for doing me the honour of requesting me to deliver this Stephen Rothman Memorial lecture and I trust that I have broadened your concept of the total picture of leprosy in relation to medicine in general and dermatology in particular. 